\title{
Determinants of Time to First Marriage Among Rural Women in Ethiopia
}

\author{
Yihenew Mitiku $^{1, *}$, Demeke Kiffle ${ }^{2}$, Dinberu Siyoum $^{2}$, Belay Birlie $^{2}$ \\ ${ }^{1}$ Department of Statistics, College of Natural \& Computational Science, Assosa University, Assosa, Ethiopia \\ ${ }^{2}$ Department of Statistics, College of Natural \& Computational Science, Jimma University, Jimma, Ethiopia \\ Email address: \\ yihenew.mt@gmail.com(Y.Mitiku),demeks10@gmail.com(D. Kiffle),dinberu.seyoum@gmail.com(D. Siyoum), \\ belaya.birlie@gmail.com(B. Birlie) \\ ${ }^{*}$ Corresponding author
}

\section{To cite this article:}

Yihenew Mitiku, Demeke Kiffle, Dinberu Siyoum, Belay Birlie. Determinants of Time to First Marriage Among Rural Women in Ethiopia. Biomedical Statistics and Informatics. Vol. 3, No. 1, 2018, pp. 1-6. doi: 10.11648/j.bsi.20180301.11

Received: February 23, 2018; Accepted: April 18, 2018; Published: May 9, 2018

\begin{abstract}
Age at marriage is of particular interest because it marks the transition to adulthood in many societies; the point at which certain options in education, employment, and participation in society are foreclosed. This study aimed to investigate demographic and socioeconomic factors affecting age at first marriage in Ethiopian women. The data source used for the analysis was the 2011 Ethiopian Demographic and Health Survey, which is country representative survey. The study considered 10,417 women aged 15-49 years from nine regions and one city administration. Accelerated failure time model was used for identifying factors associated with age at first marriage. The median time for age at first marriage was 17 years $(95 \%$ CI: 16.90, 17.10). Based on Akaike's information criterion (AIC) the Log-logistic accelerated failure time model was found to be the best model in describing the age at first marriage among other candidate models. The result based on this model showed that region, women's educational level, wealth index and religion significantly affect timing of first marriage. Women who had secondary and higher education prolonged time-to-first marriage by the factor of $\phi=1.42$ and $\phi=1.46$, respectively. Women from Oromia, Somali, SNNP and Dire Dawa have prolonged time to age at first marriage by $\phi=1.02, \phi=1.05, \phi=1.08$, and $\phi=1.09$ respectively. However, women from Amhara region $(\phi=0.89)$, Benishangul-Gumuz region $(\phi=0.95)$ and Gambela region $(\phi=0.95)$ had a significantly higher risk of early first marriage compared to their counterparts in the Tigray region. The acceleration factors for middle wealth index and rich are 0.99 and 0.98 respectively using poor household reference. This implied that poor household women have longer time-to-age at first marriage. Improving girls and young women access to education is important for rising the women's age at first marriage, which is vital for empowering them and enhancing their participation in any sector.
\end{abstract}

Keywords: Survival Data Analysis, Time to First Marriage, Accelerated Failure Time Model, Marriage

\section{Introduction}

Age at marriage is of particular interest because it marks the transition to adulthood in many societies; the point at which certain options in education, employment, and participation in society are foreclosed; and the beginning of regular socially acceptable time for sexual activity and childbearing [24]. Very early marriage is said to undermine other rights guaranteed by the convention, including the right to be protected from physical abuse and sexual exploitation and the right not to be separated from parents against one's will [26]. Yet many girls, and a smaller number of boys, enter marriage without any chance of exercising their right to choose. Some are forced into marriage at a very early age; others are simply too young to make an informed decision about their marriage partner or about the implications of marriage itself. On the other hand, delayed marriage, are believed to bring in the issues of dating, premarital sex, unwanted pregnancy, abortion, STDs and HIV/AIDS [15].

As in most developing countries, early marriage is prevalent in Ethiopia. The 2000 Ethiopian DHS further reveals that $31 \%$ of women aged $25-49$ years were married before age 15 and $70 \%$ of women in the same age group were married before age 18. The median age at first marriage in 
the same year was 16 years [4]. The 2005 EDHS also maintains similar trends. The report shows that, nationwide, close to $44 \%$ women aged $25-49$ were married before age 15 and $66 \%$ were married before age 18 . In 2005 , the median age at first marriage was 16.1years [5].

Having realized that there are limited studies that have been carried out in Ethiopia and the differentials and socioeconomic determinants of age at first marriage in the country are not adequately known, this study attempt to establish the differentials and determinants of age at first marriage in Rural Ethiopian setting.

\section{Methodology}

\subsection{Source of Data}

The data for this study was extracted from the published reports of Ethiopian Demographic and Health Survey [6]. It is the third survey conducted in Ethiopia as part of the worldwide DHS project. The principal objective of the 2011 EDHS was to provide current and reliable data on marriage, fertility and family planning behavior, child mortality, adult and maternal mortality, children's nutritional status, use of maternal and child health services, knowledge of HIV/AIDS, and prevalence of HIV/AIDS and anemia.

\subsection{Sampling Design}

The sample for the 2011 EDHS was designed to provide population and health indicators at the national (urban and rural) and regional levels. The 2007 Population and Housing Census, conducted by the CSA, provided the sampling frame from which the 2011 EDHS sample was drawn. Administratively, regions in Ethiopia are divided into zones, and zones into administrative units called weredas. Each wereda is further subdivided into the lowest administrative unit, called kebele. During the 2007 census each kebele was subdivided into census enumeration areas (EAs), which were convenient for the implementation of the census.

The 2011 EDHS sample was selected using two stage cluster design and EAs were the sampling units for the first stage. The sample included 624 EAs, 187 in urban areas and 437 in rural areas. Households comprised the second stage of sampling. A complete listing of households was carried out in each of the 624 selected EAs from September 2010 through January 2011. A representative sample of 17,817 households was selected for the 2011 EDHS, of these, 16,702 were successfully interviewed. In the interviewed households 17,385 eligible women were identified for individual interview; complete interviews were conducted for 16,515. Women whose current ages are 15-49 years are included in the survey. Out of all 16,515 urban and rural respondents 10,417 rural women from nine regions and Dire Dewa city administration were included in the study. The data was analyzed using R and STATA statistical soft wares.

\subsection{Variables in the Study}

\section{The Response Variable}

The response variable is time to first marriage. It is measured as the length of time from birth until the age at first marriage which is measured in years. During the survey all women were asked a series of questions regarding to their marital status and whether they had ever lived with a man. The response to this question constitutes the women age at first marriage and women who had not yet experienced the events resulting in right censoring of the data.

Explanatory Variables

Several predictors were considered in this study to investigate the determinant factors of time to first marriage. These are women education level, region, religion, women work status, wealth index, and mass media. All of these covariates are categorical.

Table 1. Coding and explanation of explanatory variables.

\begin{tabular}{|c|c|c|}
\hline Variable & Description & Categories \\
\hline Women education level & Women's level of education & $\begin{array}{l}0=\text { No education } ; 1=\text { Primary; } \\
2=\text { Secondary, } 3=\text { Higher }\end{array}$ \\
\hline Region & Women's region & $\begin{array}{l}1=\text { Tigray }, 2=\text { Affar, } 3=\text { Amhara } \\
4=\text { Oromiya }, 5=\text { Somali, } \\
6=\text { Benishangul-Gumuz, } 7=\text { SNNP, } \\
8=\text { Gambela, } 9=\text { Harari, } 10=\text { Dire Dawa }\end{array}$ \\
\hline Religion & Women's religion & $\begin{array}{l}1=\text { Orthodox }, 2=\text { Muslim, } \\
3=\text { Protestan }, 4=\text { Others }\end{array}$ \\
\hline Women work status & Women's Working status & $0=$ Not had work, $1=$ Had work \\
\hline Wealth index & Household wealth index & $1=$ Poor, $2=$ Middle, $3=$ Rich \\
\hline Mass media & Access to mass media & $0=$ No, $1=$ Yes \\
\hline
\end{tabular}

\subsection{Methods of Data Analysis}

This study was used accelerated failure time model to identify factors associated with age at first marriage.

Accelerated Failure Time Model

Although parametric models are very applicable to analyze survival data, there are relatively few probability distributions for the survival time that can be used with these models. In these situations, the accelerated failure time model (AFT) is an alternative to the Proportional hazards model for the analysis of survival time data. Under AFT models we measured the direct effect of the explanatory variables on the survival time instead of hazard. This characteristic allows for an easier interpretation of the results because the parameters measure the effect of the correspondent covariate on the mean survival time.

The AFT model states that the survival function of an 
individual with covariate $X$ at time $t$ is the same as the survival function of an individual with a baseline survival function at a time $t^{*} \exp \left(a^{\prime} X\right)$, where $a^{\prime}=\left(a_{1}, a_{2}, \ldots, a_{p}\right)$ is a vector of regression coefficients. In other words, the accelerated failure-time model is defined by the relationship.

$$
S(t \mid X)=S_{o}\left\{t * \exp \left(a^{\prime} X\right)\right\}, \text { for all X }
$$

In this study the Weibull AFT, log- logistic AFT, and lognormal AFT Models were considered.

Model Selection: For comparing models that are not nested, the Akaike's information criterion (AIC) is used which is defined as:

$$
A I C=-2 \log \mathrm{L}+2(\mathrm{k}+\mathrm{c}+1)
$$

Where $\mathrm{k}$ is the number of covariates and $\mathrm{c}$ the number of model specific distributional parameters. Lower values of the AIC suggest a better model.

\section{Results}

A total of 10,417 rural women from nine regions and Dire Dawa city administration were included in the study. Out of the total women interviewed, 2,145(20.6\%) did not get married at the time of the survey and none of the respondents had a marriage experience but unable to recall the age at first marriage (Left censored). Majority of the respondents, $8,272(79.4 \%)$ were married at the time of the survey or had an experience before. About $12.2 \%$ of the respondents were from Tigray, 9.8\% from Affar, 16.2\% from Amhara, 16.1\% from Oromia, 5.5\% from Somali, 9.9\% from BenishangulGumuz, 15.1\% from SNNP, 7.7\% from Gambela, 4.1\% from Harari region and the rest $3.4 \%$ from Dire Dawa.

With regard to educational attainment, about $64.3 \%$ of the respondents had no education, while $32.9 \%$ had primary education, and $2 \%$ had attended secondary education. About $64.6 \%$ of the women respondent had no any access of mass media. About $53.7 \%$ of the household's were classified as poor while $19.8 \%$ had middle income and $26.6 \%$ were rich. More than half $(70 \%)$ of the women respondents had no work. Of the total women, $35.1 \%$ were Orthodox, $42.3 \%$ Muslim, $19.6 \%$ Protestant, and $3 \%$ of them were from other religion followers at the time of the survey. The overall median time of age at first marriage for Rural Ethiopian women is 17 years with $95 \% \mathrm{CI}$; $(16.90,17.10)$.

Accelerated Failure Time Model Results

The datasets was fitted using Weibull, log-logistic and lognormal AFT model. For age at first marriage data, multivariable AFT models of weibull, log-logistic, and lognormal distributions were fitted by including all the covariates those are significant in the univariable analysis at $20 \%$ level. To compare the efficiency of different models, the AIC was used. A model having the minimum AIC value was preferred. Accordingly, Log-logistic AFT model (AIC = 46,830.22) found to be the best for age at first marriage data sets from the given alternatives when including all the covariate those are significant in the uni-variable analysis. AFT models and the corresponding AIC values are displayed in table 2.

Table 2. Comparison of AFT Models Using AIC.

\begin{tabular}{ll}
\hline Baseline Distribution & AIC \\
\hline Weibull & $49,916.13$ \\
Log- logistic & $46,830.22$ \\
Log- normal & $47,228.63$ \\
\hline
\end{tabular}

From the log-logistic accelerated failure time model, Women's educational level when using no education as reference and religion (Orthodox as reference) prolong timeto-age at first marriage, while wealth index when using poor as reference and some categories of region when Tigray was reference statistically significantly shorten time-to-age at first marriage in Rural Ethiopia.

Under the log-logistic AFT model, from region category Affar region ( $\mathrm{p}$-value $=0.181, \phi=1.02,95 \% \mathrm{CI}$ : $(0.993$, $1.039)$ ) and Harari region ( $\mathrm{p}$-value $=0.949, \phi=1.001,95 \%$ CI :( $0.9731,1.0288))$ are not significant when compare to Tigray region. From the variable religion category Muslim was not significant when using orthodox as the reference category with ( $\mathrm{p}$-value $=0.081, \phi=1.01,95 \% \mathrm{CI}$ : $(0.998$, 1.028)). Also, households with middle wealth index was insignificant by using poor households as a reference category with ( $\mathrm{p}$-value $=0.292,95 \% \mathrm{CI}:(0.983,1.005), \phi$ $=0.99$ ).

\begin{tabular}{|c|c|c|c|c|c|}
\hline Covariates & Coef & $\operatorname{Se}($ Coef $)$ & $\phi$ & $95 \%$ CI for $\phi$ & p-value \\
\hline \multicolumn{6}{|l|}{ Region } \\
\hline Tigray & Ref & & & & \\
\hline Afar & 0.01 & 0.01 & 1.02 & $(0.993,1.039)$ & 0.181 \\
\hline Amhara & -0.1 & 0.01 & 0.89 & $(0.877,0.906)$ & 0.000 \\
\hline Oromiya & 0.02 & 0.01 & 1.02 & $(1.001,1.041)$ & 0.036 \\
\hline Somali & 0.05 & 0.01 & 1.05 & $(1.022,1.075)$ & 0.000 \\
\hline Benishangul-G & -0.06 & 0.01 & 0.95 & $(0.926,0.965)$ & 0.000 \\
\hline Gambela & -0.05 & 0.01 & 0.95 & $(0.925,0.969)$ & 0.000 \\
\hline Harari & 0.001 & 0.01 & 1.001 & $(0.974,1.029)$ & 0.949 \\
\hline Dire Dawa & 0.09 & 0.02 & 1.09 & $(1.060,1.126)$ & 0.000 \\
\hline \multicolumn{6}{|c|}{ Women education level } \\
\hline No education & Ref & & & & \\
\hline Primary & 0.1283 & 0.01 & 1.14 & $(1.126,1.148)$ & 0.000 \\
\hline Secondary & 0.3526 & 0.02 & 1.42 & $(1.369,1.478)$ & 0.000 \\
\hline
\end{tabular}

Table 3. Log-logistic Multi-variable AFT Model for Age at First Marriage data. 


\begin{tabular}{|c|c|c|c|c|c|}
\hline Covariates & Coef & Se(Coef) & $\phi$ & $95 \%$ CI for $\phi$ & p-value \\
\hline Higher & 0.3762 & 0.03 & 1.46 & $(1.380,1.540)$ & 0.000 \\
\hline \multicolumn{6}{|l|}{ Wealth index } \\
\hline Poor & Ref & & & & \\
\hline Middle & -0.0062 & 0.01 & 0.99 & $(0.983,1.005)$ & 0.292 \\
\hline Rich & -0.0246 & 0.01 & 0.98 & $(0.965,0.987)$ & 0.000 \\
\hline \multicolumn{6}{|c|}{ Women work status } \\
\hline Not had work & Ref & & & & \\
\hline Had work & -0.004 & 0.00 & 0.99 & $(0.986,1.006)$ & 0.419 \\
\hline \multicolumn{6}{|l|}{ Religion } \\
\hline Orthodox & Ref & & & & \\
\hline Muslim & 0.01 & 0.01 & 1.01 & $(0.998,1.028)$ & 0.081 \\
\hline Protestant & 0.02 & 0.01 & 1.02 & $(1.006,1.039)$ & 0.009 \\
\hline Others & 0.01 & 0.01 & 1.01 & $(0.986,1.043)$ & 0.328 \\
\hline
\end{tabular}

Coef : coefficient, Se: Standard error, $\phi$ : acceleration factor, CI : Confidence interval, Ref : Reference

From table 3 the estimated acceleration factor for women from Amhara, Oromia, Somali, Benishangul-Gumuz, SNNP, Gambela and Dire Dawa is estimated to be 0.89, 1.02, 1.05, $0.95,1.08,0.95,1.09$ with $95 \% \mathrm{CI}$; $(0.877,0.906),(1.001$, $1.041),(1.022,1.075),(0.926,0.965),(1.054,1.099),(0.925$, $0.969),(1.06,1.126)$ respectively by using Tigray region as reference category. This indicates women from Oromia, Somali, SNNP and Dire Dawa have prolonged time to age at first marriage and time-to-age at first marriage decreased in Amhara, Benishangul-Gumuz and Gambela region than Tigray region women.

The acceleration factors for women attending primary education, secondary education, and higher are 1.14, 1.42, and 1.46 with $95 \% \mathrm{CI}$; $(1.126,1.148),(1.369,1.478),(1.38$, 1.54) respectively. These confidence intervals does not include one in all category; indicating primary, secondary and higher education's were significantly important factors for the timing of age at first marriage by using uneducated women as a reference category. This indicates that women with primary, secondary and higher education prolonged age at first marriage.

The acceleration factors for middle wealth index and rich are 0.99 and 0.98 with $95 \% \mathrm{CI}$; $(0.983,1.005)$, and $(0.965$, $0.987)$ respectively by using poor household as reference. This implied that poor house hold women had longer time-toage at first marriage, however the difference is not significant for middle and poor house hold wealth index $(\mathrm{P}=0.292)$. The acceleration factor for protestant religion was 1.02 with $95 \%$ CI: $(1.006,1.04)$ by using Orthodox as reference category. This result suggested that women from Protestant religion had longer time-to-age at first marriage than women from Orthodox religion.

\section{Discussion}

The findings of this study revealed that wealth index and Amhara, Benishangul-Gumuz and Gambela region have a significantly shorter time-to-age at first marriage while women's educational level, religion, and from region category (Oromia, SNNP and Dire Dawa) prolonged time-toage at first marriage among women in Rural Ethiopia. About $67.1 \%$ of women were married before age of 18 years. This indicates that early marriage is highest in Ethiopia. The median time of age at first marriage for Rural Ethiopian women was 17 years with 95\% CI; (16.90, 17.10).

The findings of this study suggested that women's educational level had a significant effect on time to age at first marriage with 5\% level of significance and it prolonged age at first marriage by the factor of $\phi=1.14, \phi=1.42$ and $\phi$ $=1.46$ for primary, secondary and higher education respectively when compared to illiterate women. The result of the study shows that woman who had higher education was more survived than those uneducated and primary education. A similar study conducted in Ethiopian by Tezera (2013) used data from 2011 EDHS to examine the effect demographic and socioeconomic variables to determine early marriage among women. The result of the study showed that educational level of women was found to be significant predictors for early marriage. Similar study in Malawi by Palamuleni (2011) also found that women education were statistically significant factor of age at first marriage. Also, Agaba et al (2011) indicates that educational attainment were strong socio-economic determinants of first marriage in Western Uganda.

The results of this study suggested that region was significant predictive factor for the timing of age at first marriage of women in Rural Ethiopia. Women in the Oromia region, Somali region, SNNP region and Dire Dawa administration prolong age at first marriage by a factor of $\phi$ $=1.02, \phi=1.05, \phi=1.08$, and $\phi=1.09$ respectively compared to those in the Tigray region. However, women from Amhara region $(\phi=0.89)$, Benishangul-Gumuz region $(\phi$ $=0.95)$ and Gambela region $(\phi=0.95)$ had a significantly higher risk of early first marriage compared to their counterparts in the Tigray region. A study conducted by Tezera (2013) to examine the effect demographic and socioeconomic variables to determine early marriage among women in Ethiopia. The result of the study revealed that region of women was significant predictor for early marriage. A similar study in Nigeria by Adebowale et al. (2012) also found that region was significantly associated with the timing of first marriage. Also another study in Vietnam by Lung $\mathrm{Vu}$ (2009) finds that region was significantly related to age at first marriage.

The result of this study revealed that household wealth index were significantly shortened time to age at first 
marriage in Rural Ethiopian women. Compared to rich women, poor women had relatively lower risk of first marriage. This result contradicts with a study by Kamal (2011) in the Ethnic Tribal women in Bangladesh. The findings revealed that Parents' economic status had the most significant effect on marital timing. The higher the economic status of the parents, the lower is the probability of age at earlier marriage. Studies elsewhere suggest the opposite of this, with poor women having a relatively higher risk of first marriage (Haloi and Limbu, 2013; Hoq, 2013).

The result of this study also revealed that religion was an important factor for age at first marriage of women in Rural Ethiopia. Women from protestant religion had prolonged age at first marriage by a factor of $\phi=1.03$ as compared to Orthodox. These findings are similar to Tezera (2013) in Ethiopia and the study showed that religion of women was found to be significant predictors for early marriage. The same study in Nigeria by Adebowale et al. (2012) found religion were significantly associated with the timing of first marriage. Another study by Agabaet al (2011) religion is strong social determinant of first marriage in Western Uganda. This result is consistent with Erulkar (2013) in Ethiopia, Abdallah (2011) in Nigeria, Bayisenga (2012) in sub-Saharan Africa, Ikamari LD, (2005) in Kenya.

\section{Conclusions}

The main objective of this study was modeling the determinant of age at first marriage by using AFT models. The result of Log-logistic AFT model showed that region, women's educational level, wealth index and religion were found significant predictors to age at first marriage among women in Rural Ethiopia. Among these significant predictors, women's educational level and religion of women prolong age at first marriage while wealth index of the family shortens timing of first marriage.

The study findings reveal that education is the most significant variable affecting age at first marriage in rural Ethiopia. Therefore, it is important that government policies promote the status of women in rural Ethiopia by helping them to have more access to education so that they can make their own decision regarding when to get married. It is crucial to continue improving girls and young women access to education is important for rising the women's age at first marriage, which is vital for empowering them and enhancing their participation in any sector. The education system should aim at providing life skills to enable girls avoid early marriage as well as providing reproductive health information so that they are aware of the advantages of delayed marriage.

\section{List of Abbreviations}

$$
\begin{aligned}
& \mathrm{AFT}=\text { Accelerated Failure Time } \\
& \mathrm{AIC}=\text { Akaike Information Criterion } \\
& \mathrm{CI}=\text { Confidence Interval } \\
& \mathrm{CSA}=\text { Central Statistics Agency } \\
& \mathrm{DHS}=\text { Demographic and Health Survey }
\end{aligned}
$$

$\mathrm{EAs}=$ Enumeration areas

EDHS= Ethiopian Demographic and Health Survey

HIV/AIDS= Human Immune deficiency Virus/Accuired Immune deficiency Syndrome

STDs $=$ Sexual Transmitted Diseases

\section{Declarations}

Ethics approval and consent to participate

Human subject research approval for this study was received from Jimma University Research Ethics Committee.

\section{Availability of Data and Materials}

The data sets analyzed in this study available from the corresponding author on reasonable request. The $\mathrm{R}$ code used to analyze the data provided as a supplement of the article.

\section{Conflict of Interest}

The authors declare that they have no competing interests.

\section{Funding}

All the authors do not have any possible conflicts of interest.

\section{Author's Contributions}

YM contributed to the study concept and design, performed the analysis on the data set as well as wrote the first draft of the paper. BB and DK contributed to the analysis and interpretation of the data, in addition to drafting and critical revision of the manuscript. DS contributed to the study concept and design. All authors read and approved the final manuscript.

\section{References}

[1] Abdallah, B. A. (2011): Girl Child Marriage and Women Development in Nigeria: Contemporary Issues", Journal of Development and Psychology 14(9): pp.248-259.

[2] Adebowel A., Fagbamigbe A., Okareh O. and Lawal O. (2012). Survival Analysis of Timing of First Marriage among Women of Reproductive age in Nigeria: African Journal of Reproductive Health.

[3] Agaba. P, Atuhaire. L. K, Rutaremwa. G (2011), Determinants of Age at First Marriage among women in Western Uganda. SSAE, Makerere University, Uganda.

[4] Bayisenge, J. (2012): "Early Marriage as a Barrier to Girl's Education: A Developmental Challenge in Africa", Journal of Social Psychology 12(6): pp. 23-48.

[5] Blossfeld Hans-Peter, Jaeniches Ursula. (1992). Educational Expansion and Changes in Women's Entry into Marriage and Motherhood in the Federal Republic of Germany, Journal of Marriage and the Family 54 (2):302-315. 
[6] Central Statistical Authority and ORC Macro. (2001). Ethiopia demographic and health survey 2000. Addis Ababa, Ethiopia and Calverton, Maryland, USA: Central Statistical Authority and ORC Macro.

[7] Central Statistical Agency and ORC Macro. (2006). Ethiopia demographic and health survey 2005. Addis Ababa, Ethiopia and Calverton, Maryland, USA: Central Statistical Agency and ORC Macro.

[8] Central Statistical Agency, (2011). Ethiopian Demographic and Health Survey, Addis Ababa, Ethiopia.

[9] Clark, S. (2004). "Early Marriage and HIV Risks in SubSaharan Africa," Studies in Family Planning, 35(3), 149160. [Online]. Available:

http://www.ncbi.nlm.nih.gov/pubmed/15511059.

[10] Cox, D. R. (1972). Regression Models and Life Tables (with discussion), Journal of the Royal Statistical Society, Series B, $34(2)$.

[11] Erulkar, A. (2013). Early marriage, marital relations and intimate partner violence in Ethiopia. International Perspectives on Sexual and Reproductive Health, 39(1), pp.613.

[12] Haloi, A. and Limbu, D. K. (2013). Socio-economic factors influencing age at first marriage of Muslim women of a remote population from North East India, Antrocom Online

[13] Hoq, M. (2013). Regional differentials in age at first marriage among women in Bangladesh, Asian Journal of Applied Science and Engineering 2 (2)76-83.

[14] Ikamari LD, (2005). The effect of Education on the Timing of Marriage in Kenya. Demographic Research volume 12, article 1, pp 1-28: Feb. 2005.

[15] Jones GW (2007). "Delayed Marriage and Very Low Fertility in Pacific Asia." Popul. Dev. Rev., 33(3): 453-478.

[16] Kamal S. M. Mostafa (2011). Socio-Economic Determinants of Age at First Marriage of the Ethnic Tribal Women in Bangladesh, Asian Population studies.

[17] Kaplan, E. L. and Meir, P. (1958). Nonparametric estimation from incomplete observations. Journalof the American
Statistical Association, 58(282):457-481.

[18] Lesthaeghe R, Kaufmann G, Meekers D (1989). The Nuptiality regimes in sub- Saharan Africa. in Lesthaeghe, R. (ed) Reproduction and Social Organization in Sub-Saharan Africa, University Of California Press, Berkeley.

[19] Lung Vu (2009). Age at first marriage in Vietnam: Trends and determinants. Paper presented at Population Association of America (PAA), April 30- May 2.

[20] Mensch Barbara S., Suchela Singh, and John B. casterline. (2005). Trends in the Timing of First Marriage Among Men and Women in The Developing World. Population council, No. 202.

[21] National Committee on Traditional Practices of Ethiopia. (2003). Ethiopia harmful traditional practices: Old beyond imaginings Addis Ababa.

[22] National Research Council and Institute of Medicine of the National Academies (NRC-IOM).2005. Growing Up Global: The Changing Transitions to Adulthood in Developing Countries. Ed. Cynthia B. Lloyd. Washington, DC: The National Academies Press. New York.

[23] Palamuleni. E. Martin, (2011). Socioeconomic determinants of age at first marriage in Malawi. International Journal of Sociology and Anthropology vol. 3(7), pp224-235.

[24] Population Council (2004). Supporting Married Girls: Calling Attention to a Neglected Group.

[25] Population Council, (2002). Background document prepared for working group on Girls, United Nations Special Session on Children, 10 may, New York.

[26] Tezera A. (2013). Determinants of Early Marriage among Women in Ethiopia.

[27] United Nations, (2000). World Marriage Patterns. New York: Population Division.

[28] Wienke, A. (2011). Frailty Models in Survival data. Chapman and Hall, New York, 1 edition. 